ARS Atílio Avancini e Fernanda Riscali*

ano 16

n. 33

\title{
Revolução visual da arte de Eisenstein em Ivan, o Terrível.
}

Eisenstein's visual revolution of the art in Ivan, the Terrible.

Artigo inédito

palavras-chave: mensagem cinematográfica; produção cultural; crítica de arte; construção estética; análise do fotograma

keywords:

movie message; cultural production; art critical: aesthetic construction; frame analysis

* Universidade de São Paulo

[USP].
A proposta do artigo é a leitura da mensagem cinematográfica e fotográfica do filme Ivan, o Terrivel - Parte II do diretor Sergei Eisenstein. A metodologia de pesquisa tem como ponto de partida a análise do fotograma idealizado pelo crítico Roland Barthes entre os sentidos óbvio e obtuso. Em adição, ampliase a circulação de sentidos do objeto artístico para o ponto de vista descritivo e cultural de Erwin Panofsky, além da leitura do elemento técnico-estético. Instrumento de denúncia, a obra clássica Ivan, o Terrível - Parte II se eterniza ao ser legitimado como registro histórico do passado e metáfora do presente. Esta pesquisa, de caráter teórico e crítico na área da Arte, trabalha com a ideia de que com lirismo plástico e discussão política esta obra cinematográfica contribui para promover uma revolução visual.

The proposal of the article is the reading of the movie and photographic message of the film Ivan the Terrible - Part II by the director Sergei Eisenstein. The research methodology has as its starting point the analysis of the frame devised by the critic Roland Barthes between the obvious and obtuse. In addition, the circulation of meanings of the artistic object is extended to the descriptive and cultural of Erwin Panofasky, besides the lecture of the point of view technical-aesthetic. An instrument of denunciation, the classic Ivan, the Terrible - Part II is perpetuated by being legitimized as a historical record of the past and a metaphor of the present. This research in the area of art theory and critic, works with the idea that with plastic lyricism and political discussion this cinematographic work contributes to promote a visual revolution. 
Este artigo discute os fundamentos e conceitos teóricos da mensagem fotográfica e cinematográfica do crítico e semiólogo Roland Barthes, embora seja constatado que Barthes é ponto de partida e não consegue abarcar a problemática complexa de interpretar uma obra fotográfica e cinematográfica. Ao analisar o artefato primeiro do cinema - a fotografia -, a fundamentação teórica de Barthes engloba dois conceitos sobre o fotograma: o sentido óbvio (patamar informativo e simbólico) e o sentido obtuso (patamar poético e fílmico). $\mathrm{O}$ método foi publicado originalmente na revista Cahiers du Cinéma (número 222), em 1970. E depois editado no capítulo "O terceiro sentido" ("Le troisième sens") do livro O óbvio e o obtuso (L'obvie et l'obtus). O terceiro sentido, no caso, é o sentido obtuso, que excede os dois patamares do sentido óbvio.

Nesta pesquisa, o filme Ivan, o Terrível - Parte II de Sergei Eisenstein é o objeto de estudo para a análise de sentidos cinematográficos. Esta atividade, portanto, vai se concentrar fundamentalmente em três fragmentos estáticos (fotogramas ou frames) do final deste filme, isto é, na sequência colorida do banquete. Parte-se da hipótese de tratar-se de uma sequência matricial, uma vez que seus elementos ecoam em todo o filme e a noção do todo permanece. Pela paralisia da imagem em movimento do cinema, para que seja lida em termos de três imagens still, a análise de sentidos tem por objetivo afirmar que sua construção conceitual e estética explicita o conteúdo do filme. Ou seja, é um vestígio representativo do todo. No livro O sentido do filme (1937), capítulo "Palavra e imagem", Sergei Eisenstein já referenda o conceito de que cada plano pode demarcar uma parcela que corresponde ao sentido geral do filme.

Os textos reunidos em O óbvio e o obtuso são ainda pertinentes, embora criados a partir de outros paradigmas comunicacionais e fundamentados pelo pressuposto indicial da fotografia: a visão

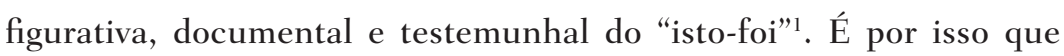
neste artigo trabalha-se com os princípios fundantes de Barthes. Mas amplia-se a circulação de sentidos do objeto artístico enfocado para outros dois elementos de Erwin Panofsky (Significado nas Artes Visuais, 1976): a descrição e a análise cultural dos frames. Além de um último elemento: a leitura do ponto de vista técnico-estético. Pois o próprio Barthes sempre buscou a interpretação criativa num campo do saber em rica discussão e sem conceber algo fechado ou definitivo.
Atílio Avancini e Fernanda Riscali

Revolução visual da arte de Eisenstein em Ivan, o Terrível.
1. BARTHES, Roland. La chambre claire. In: Cuvres complètes (tome V). Paris: Éditions du Seuil, 2002, p. 793. 
Justifica-se a pertinência de retomar a obra clássica de

2. AUMONT, Jacques.; MARIE, Michel. L'analyse des films. Paris: Nathan, 1988, p. 29.

3. GROYS, Boris. Stalinism as aesthetic phenomenon. In: EFIMOVA, A. \& MANOVICH, L. (org.). Tekstura. Chicago: The University of Chicago Press, 1993, p. 118 fotografia, o cinema, as artes e o complexo mundo contemporâneo. Busca-se também traçar um paralelo entre o poder de previsão do filme e a atual conjuntura política russa e mundial. Este método de leitura da mensagem fotográfica e cinematográfica é também importante contribuição aos estudos de produção de sentidos imagéticos por se originar de áreas interdisciplinares.

Antes de aplicar o método barthesiano como princípio de interpretação de sentidos e desenvolver a descrição narrativa e a análise cultural de Panofsky (além da explicitação dos elementos técnico-estético dos três fotogramas do filme Ivan, o Terrível - Parte II), faz-se necessário desenvolver breve relato sobre as manifestações da vanguarda artística soviética do início do século $\mathrm{XX}$, envolvendo principalmente os nomes de Sergei Eisenstein e Aleksandr Ródtchenko. Vale ainda dizer que para o pensamento de Jacques Aumont e Michel Marie não existe método universal para analisar um filme cinematográfico. E que a análise fílmica é sempre interminável, além de ser a base da reflexão de caráter teórico e crítico sobre o próprio cinema ${ }^{2}$.

\section{Cinema de conflito}

A transgressão do diretor cinematográfico Sergei Eisenstein está na produção de sentidos pela teoria da montagem, mas também pelo minucioso trabalho visual na composição de imagens. A partir dos anos 1930, a discriminação estética na União Soviética não foi só contra o movimento formal na arte, "mas contra a forma artística como tal”3. As regras ditadas pelo marechal Josef Stalin (1878-1953) obrigou o teatro, o cinema, a literatura, a música, as artes plásticas e a fotografia a seguirem padrões ideológicos, excluindo linguagens complexas e retratando os heróis de modo positivo. Dentre outros, o nacionalismo incentivado pelo secretário geral do Partido Comunista da União Soviética impôs à arte a hegemonia conceitual do "realismo socialista”.

A obra de Eisenstein, na dimensão estética e interface social, valoriza o entusiasmo soviético. E trabalha com a tese de que com lirismo plástico e discussão política o cinema artístico pode contribuir para fazer a revolução. Esse princípio, desde a produção do frame à 
montagem, traduz a missão criativa e sociocultural do diretor soviético. Eisenstein pensa o cinema de conflito sob o prisma da revolução - a dicotomia entre tese e antítese, a superação dada pela síntese -, como na visão marxista de que "a história nada mais é do que a constante transformação da natureza humana" ${ }^{4}$. A montagem por conflito inspira-se no materialismo dialético. O ser humano é constante evolução na interação de forças em oposição ao materialismo histórico, ou seja, dialogando diretamente com o socialismo de Karl Marx e Friedrich Engels.

$\mathrm{O}$ cineasta volta suas lentes à história e lutas do povo russo. O objetivo primeiro é recontá-las e arrancar emoções da plateia pelo movimento formal na arte. Isto é, fazer com que os distintos elementos técnico-estéticos do filme promovam discursos de significação pela interação de opostos. A concepção da arte como conflito é, em Eisenstein, assimilada pelo trabalho de seu diretor de fotografia Eduard Tissé, que sabe explorar os aspectos da técnica e da estética: cor, iluminação, foco, forma, linha, plano, ângulo, perspectiva, textura. Além de outros segmentos: narrativa, narrador, ator, teatralidade, roteiro, fotografia, figurino, cenário, montagem, legenda, trilha sonora.

O ponto determinante em Eisenstein é a montagem, também caracterizada pela dimensão metafórico-poética do conflito e da irregularidade. A colisão dentro do quadro composicional é proveniente da somatória de alguns pares antagônicos de elementos plásticos, assim descritos por Eisenstein: "plano (primeiro e geral), direção gráfica, volume de variadas dimensões, iluminação (claro e escuro), escala (dimensão do objeto), cronologia (tempo de duração), ângulo de tomada" . Entre 1927 e 1928, Eisenstein se torna profissional reconhecido graças ao sucesso na Alemanha de $O$ encouraçado Potemkin.

Eisenstein lançou seu primeiro manifesto teórico sobre a sétima arte, "A Montagem de Atrações", publicado na revista LEF, que era editada pelo poeta Vladimir Mayakovsky. Neste artigo, ele defendia que os espectadores deveriam ser tomados de surpresa por choques emocionais bem calculados cujo objetivo seria causar agitação. Para tanto, algumas imagens deveriam ser escolhidas independentemente da ação e apresentadas não em sequência cronológica, mas de um modo que pudessem criar um máximo de
Atílio Avancini e

Fernanda Riscali

Revolução visual da arte de

Eisenstein em Ivan, o Terrível.

4. MARX, Karl. A miséria da filosofia. São Paulo: Editora Ícone, 2004, p. 170.

5. EISENSTEIN, Sergei. 0 sentido do filme. Rio de Janeiro: Jorge Zahar, 2002a, p. 15 
6. VIANNA, Alexander Martins. Eisenstein e o cinema soviético. Blog da Revista Espaço Acadêmico, 15 ago. 2012. Disponível em: <https:// espacoacademico.wordpress. com/2012/09/12/eisensteine-o-cinema-sovietico-ii/>. Acesso em: 11 jul. 2018. impacto psicológico. Deste modo, o diretor comunicaria suas ideias para o espectador, conduzindo-o de um estado psicológico anterior para o nascimento de uma nova consciência. Tais princípios básicos da dialética na montagem guiaram toda a sua carreira ${ }^{6}$.

\section{Manifestações da vanguarda artística}

No período compreendido entre o final do século XIX até meados dos anos 1930, a Rússia, e posteriormente a União Soviética, conhece uma série de mudanças artísticas. No início do século XX, Vladimir Ulyanov (1870-1924), conhecido pelo pseudônimo de Lênin, chefe de governo da República Russa de 1917 a 1922 e da União Soviética de 1922 a 1924, já se refere à importância do cinema dentro das artes. Em oposição à europeização cultural que se estabelece no país desde o século XVII, os artistas passam a se rebelar com o padrão ocidental e criam uma nova arte: o resgate da tradição dos ícones, a busca das raízes culturais do povo, o rompimento com a ideia de imitação da natureza. E resgatam a forma como expressão da riqueza interior do artista.

Os chamados "construtivistas" ou "formalistas" pensam a imagem como construção e não como representação. A ideologia socialista e revolucionária impregna as vanguardas em geral e a arte se coloca a serviço do povo. O princípio básico que norteia os "formalistas" deriva do pensamento estabelecido no Curso de Estética do filósofo alemão Georg Hegel (1770-1831). Segundo este, a forma é veículo que se adequa ao conteúdo, ou seja, ideia tornada visível. Desse modo, pela forma seria possível compreender a obra, a sociedade que a produziu e o artista que a concebeu.

Após a queda do regime czarista em 1917, a sociedade soviética é documentada pela arte visual do fotógrafo Aleksandr Ródtchenko (1891-1956), atuante entre 1924 e 1954. Entre a fotografia de Ródtchenko e o cinema de Eisenstein há paralelos, principalmente no poder informativo e simbólico das imagens. A ideia de apresentar o artista Ródtchenko é contextualizar Eisenstein não como fato isolado, mas parte do grande movimento para promover a arte como vanguarda cultural e formação educativa. A fotografia soviética se torna valorizada no início dos anos 1930, quando é formado o grupo fotográfico Outubro, que controla o principal periódico fotográfico da época, a revista Proletárskoe Foto (Fotografia Proletária). 
Críticos oficiais viam o grupo Outubro como algo sujeito a "influências de esquerda”, e seus membro eram rotulados não só de "esquerdistas", mas de "formalistas pequeno-burgueses", incapazes de compreender os problemas reais da luta de classes. Ródtchenko destacou-se como líder do grupo. Como artista, era mais velho e mais experiente que seus associados. Todos eles tentavam ser inovadores. Suas fotos representavam experimentos ousados, e cada abordagem era levada ao extremo: ângulos e inclinações agudíssimos, contrastes máximos entre o primeiro plano e o fundo, temas "intensificados", abundância de formas em um único enquadramento. Os trabalhos de Ródtchenko influenciaram o surgimento de todo um novo movimento de fotografia experimental, à semelhança de sua pintura experimental e da arte gráfica dos anos 1910. Seus trabalhos dos anos 1920 marcaram um estilo especial na fotoarte, encorajando a formação da "fotografia de esquerda", do fotoconstrutivismo. ${ }^{7}$

O trabalho de Ródtchenko é favorecido pelo final da I Guerra Mundial e pela ambiência da liderança de Lênin e Trotsky, que lançam as palavras de ordem "pão, paz, terra e liberdade", pressuposto de um socialismo como sistema político e econômico no qual se propunha a coletivização dos meios de produção e um Estado sem classes sociais. "A fotografia deixou de ser secundária e de imitar técnicas da gravura, pintura ou tapeçaria. Ao encontrar caminho próprio ela floresce e o vento fresco traz um perfume peculiar à fotografia. Novas possibilidades se descortinam" .

Em artigo na revista Soviétskoe Foto (Fotografia Soviética), "A Fotografia é uma arte” (1934), Ródtchenko evidencia em seu trabalho o foco na vida urbana, considerando "os contrastes da perspectiva, da luz e da forma; os pontos de vista com encurtamentos exagerados; os momentos inéditos de movimento; a criação de momentos inexistentes por meio da montagem e a impressão de uma fotografia dentro de outra" . O slogan "nosso dever é experimentar" sinaliza o efeito comunicativo, simbólico, artístico e poético das imagens.

$\mathrm{O}$ cinema adere à experimentação das ideias de vanguarda, mas tem como diferencial o fato de os filmes serem distribuídos em larga escala. Por ser arte coletiva, Eisenstein afirma que o cinema é feito por trabalhadores. Esse conceito parece evitar a exaltação da tecnologia, a soberba do diretor e o princípio comercial da autoria. A ascensão do stalinismo, entretanto, não promove o estímulo à expressão

\section{Atílio Avancini e}

Fernanda Riscali

Revolução visual da arte de

Eisenstein em Ivan, o Terrível.

7. LAVRÉNTIEV, Aleksandr. Aleksandr Ródtchenko: começos da vanguarda fotográfica na Rússia. In: RÓDTCHENKO, A. Aleksandr Ródtchenko. São Paulo: IMS, 2010, p. 209.

8. RÓDTCHENKO, Aleksandr Aleksandr Ródtchenko. São Paulo: IMS, 2010, p. 10.

9. Ibidem. 
artística e ao experimentalismo formal. Há o declínio geral da originaano 16

10. CARVALHO, Luiz Gustavo. Assim vivíamos. Curador da exposição fotográfica de Vladimir Lagrange. Caixa Cultural, São Paulo, 2015.

11. EISENSTEIN, Sergei. Sobre a questão da abordagem materialista da forma. KinoJournal ARK, Moscou, n. 4-5, 1925, p. 5.

12. ALBERA, François. Eisenstein e o construtivismo russo. São Paulo: Cosac \& Naify, 2002, p. 244

lidade criativa e da autonomia comunicativa: a produção de sentidos da cultura está direcionada ideologicamente e a União Soviética fica conhecida como "país fantasma"10. Comunicadores, escritores, atores e artistas deixam o país. A polaridade se desenvolve entre o mito do futuro radioso e as condições desumanas de sobrevivência, desrespeito à democracia e liberdade pessoal.

Dziga Viértov (1896-1954), diretor soviético de cinema documental urbano e teórico do princípio câmera-olho, autor do filme $O$ homem e sua câmera (1929), atua contra o roteiro ficcional, preferindo os registros imagéticos puristas da vida espontânea. Eisenstein é acusado por Viértov pela encenação e sem utilizar o recurso do improviso. Assim, Eisenstein responde em artigo jornalístico, "Sobre a questão da abordagem materialista da forma", que "não pretende afastar-se da arte e aí está a sua força" ${ }^{11}$. Eisenstein, entretanto, busca criar suas cenas preferencialmente em cenários reais, fazendo avançar sua pesquisa experimental sobre a forma, a iluminação, a montagem, a trilha sonora.

Os filmes mudos e monocromáticos A greve (Statchka, 1924) e O encouraçado Potemkin (Broemienosets Potemkim, 1925) são lutas claramente construtivistas na expressão do cinema de autor, principalmente nas tomadas cênicas do massacre a inocentes pela guarda e cavalaria czarista na Vila Operária e na escadaria de Odessa - representação de fatos reais ocorridos antes da revolução de outubro de 1917. Nesses dois filmes há uma relação com os elementos técnico-estéticos de Ródtchenko, que também informa o povo iletrado pelas imagens: ângulos, inclinações, contrastes, abundância de formas.

Ao passar do teatro ao cinema, Eisenstein conserva vários traços de seu trabalho anterior. A encenação excêntrica, o recurso à máscara, a utilização de cenários reais, a referência à máquina, o lugar e valor dos objetos, tudo isso nutre A Greve. Por outro lado, a organização da imagem aparenta-se bastante com construções de artistas construtivistas e com o linearismo de Ródtchenko. ${ }^{12}$

Eisenstein e Ródtchenko influenciam-se mutuamente. Isso fica patente na imagem Degraus (fig. 1), feita a partir de estruturação geométrica: uso da diagonal principal e perspectiva, além de inusi- 


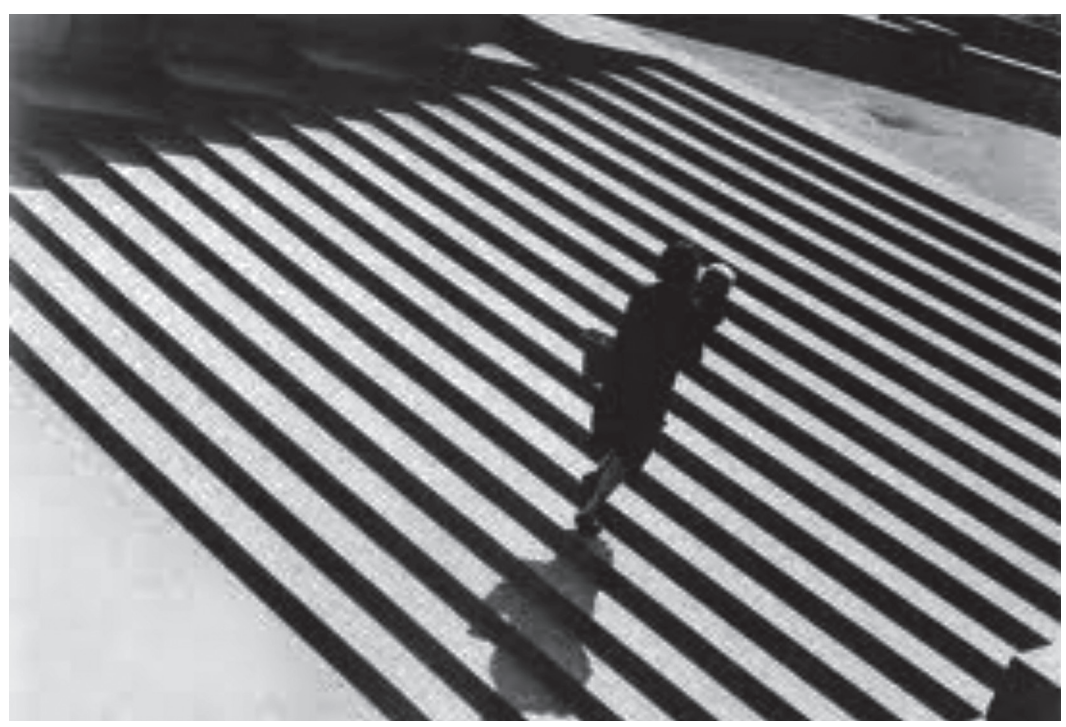

tado ponto de vista de cima para baixo. A fotografia produzida por Ródtchenko assemelha-se aos planos da escadaria de Odessa, no filme O encouraçado Potemkin, cujo movimento de pessoas é descendente na representação da rebelião dos marinheiros de 1905. Tanto no filme de Eisenstein, quanto na foto de Ródtchenko, observa-se o mesmo ângulo de incidência do contraluz, que é responsável pela sombra e pelo desenho bem marcado das escadas. Na fotografia, a ascensão dos corpos e da sombra ocupa a diagonal da imagem. A mulher e o filho de colo podem ser interpretados como metáfora visual de movimento ascendente para elevar a gente russa.

A partir dos anos 1930, a única forma de arte admitida na União Soviética é a ideologia que expressa os interesses da classe dominante pela mensagem objetiva e direta. A vanguarda artística, durante o regime stalinista, é considerada abordagem "formalista" e mecânica da realidade. Ou seja, os cânones do "realismo socialista" buscam afastar os significados indiretos ou os sentidos figurados por meio de comparações implícitas. Trata-se de dogma do regime burocrático para impedir a continuidade das manifestações vanguardistas progressistas de esquerda. É por isso que o trabalho de Eisenstein acolhe o humanismo ao lidar criativamente com as dimensões da montagem, simbolismo, metáfora e aprimoramento estético.

No governo de Josef Stálin opositores e dissidentes são confinados em campos de trabalho forçado. De fato, no final de sua
154

Atílio Avancini e

Fernanda Riscali

Revolução visual da arte de

Eisenstein em Ivan, o Terrível.

Fig. 1. Fotografia de Aleksandr Ródtchenko. Degraus, 1929. 

senstein tem problemas com a censura no filme Ivan, o Terrivel Parte II. Não por acaso, o diretor fica gravemente enfermo e falece repentinamente em 1948.

13. FREITAS, Nanci de. 0 velho e o novo: tensão entre experimentação artística no cinema de Eisenstein e as demandas ideológicas soviéticas. Revista ArtCultura, Uberlândia, v. 13, n. 22, jan.-jun. 2011, p. 27.

14. MARIE, Michel. Depoimento a Atílio Avancini. Projeto Revolução visual de Sergei Eisenstein. Universidade de São Paulo, São Paulo, 14 abr. 2016.
Pesquisador incansável, Eisenstein enfrentou tensões para conciliar as exigências partidárias, na abordagem de conteúdos político-sociais, com suas experiências vanguardistas em torno de uma "dramaturgia da forma do filme", que iria caracterizar o processo fragmentário da "montagem intelectual" em filmes como O Encouraçado Potemkin (1925) e Outubro (1927). Para os ideólogos do regime soviético, na fase stalinista, a composição artística deveria estar voltada para uma recepção imediata dos significados da obra, no que passaria a ser conhecido como "realismo socialista"13.

Desde 1929, Eisenstein ensina cinema em Moscou. Em 1934, escreve o primeiro ensaio, sobre sistemas de signos e produção de sentidos no cinema, utilizando exemplos do filme $O$ encouraçado Potemkin. Em edição de caráter teórico e crítico, os 14 fotogramas selecionados pelo diretor precedem a cena mítica do massacre na escadaria de Odessa. Na sequência célebre, plano a plano, os habitantes da ucraniana Odessa enviam alimentos aos marinheiros. "A transgressão da mensagem é evidenciar o momento político, que é representado pela bandeira vermelha a tremular sobre o encouraçado"14. A violência social é fator fundamental em sua militância revolucionária. Neste recorte fílmico, o diretor explora dois princípios da forma: o estático do mastro (fotografia) e o dinâmico da bandeira (cinema). Ou seja, o cinema em preto e branco do diretor soviético faz também sugerir a cor.

\section{Poético e enigmático}

Na metodologia de análise da mensagem fotográfica e cinematográfica de Roland Barthes, o sentido óbvio (informativo e simbólico) emerge diretamente à frente do espectador na diegese - mundo instituído pela obra ou narração dramatúrgica. Já o aspecto poético, fílmico, mágico e enigmático faz promover o sentido obtuso: "pejora- 
tivo, pastiche, carnavalesco, fantasioso, vago, oscilante, elíptico" ${ }^{15}$. O autor sugere que, como o ângulo geométrico obtuso é maior do que o ângulo perpendicular, há um terceiro processo de significação excedente ao analítico e racional.

É a partir do fotograma (imagem still ou estática), portanto, que Barthes se aproxima da essência do cinema. "O fílmico não pode ser apreendido no filme 'em movimento', mas apenas nesse artefato primeiro - e maior - que é o fotograma" ${ }^{16}$. A fotografia faz parte da origem do filme: a semente primeva do cinema. Para Barthes, oframe não é pitada quimicamente retirada da substância do filme, mas é vestígio indicial do filme corrido. Filme e fotografia, portanto, dialogam numa relação de palimpsesto sem que se possa dizer que um seja superior ao outro. Se o tempo de leitura é livre para os textos escritos, o mesmo ocorre com o fotograma.

Antes de Barthes, o conceito de simbolismo do plano cinematográfico foi desenvolvido pelo próprio Eisenstein e teve uma elaboração mais direta em dois de seus textos: "Fora de quadro" (A forma do fil$m e)^{17}$ e "Palavra e imagem" (O sentido do filme $)^{18}$. Segundo o diretor, dois pedaços de filme justapostos - síntese dedutiva - geram novo conceito, um produto que é maior do que a soma das partes. Desse modo, a justaposição de duas representações resulta em uma nova imagem. Esse princípio deriva do processo de criação dos ideogramas japoneses, em que dois hieróglifos separados fundem-se na representação de algo graficamente indescritível. Eisenstein cita, dentre outros exemplos, a justaposição das imagens "água" e "olho", que resulta no ideograma "chorar"19.

Pela montagem cinematográfica, em seu princípio unificador, dois fragmentos tornam-se correlatos, resultando em uma "terceira coisa”20. Esse princípio determina o resultado final da montagem, mas também o conteúdo dos planos justapostos. Portanto, no processo de criação do filme, para materializar o todo, o diretor tem a tarefa de criar representações parciais (fotogramas, planos) do tema geral. Cada detalhe tem participação no todo. E, de fato, este princípio legitima a análise do fotograma.

O impacto do filme Ivan, o Terrivel (Partes I e II) acontece mundialmente, tanto do ponto de vista estético quanto revolucionário. Obra síntese de Eisenstein em que se manifesta uma declarada luta política em sentido amplo contra os projetos imperialistas. Dois
Atílio Avancini e

Fernanda Riscali

Revolução visual da arte de Eisenstein em Ivan, o Terrível.

15. BARTHES, Roland. L'obvie et l'obtus. Paris: Éditions du Seuil, 1982, p. 49.

16. Ibidem, p. 59.

17. EISENSTEIN, Sergei. Fora de quadro. In: A forma do filme. Rio de Janeiro: Zahar, 2002b, p. 35-48.

18. Idem. Palavra e imagem. In:_. 0 sentido do filme. Rio de Janeiro: Zahar, 2002a, p. 13-50.

19. Idem. Op. cit., 2002b, p. 36 . 20. Idem. Op. cit., 2002a, p. 17. 
ARS filmes majestosos a relatar a tomada do poder pelo czar Ivan, a consano 16 piração dos boyars e as lutas finais de Ivan. "Mas ninguém, nunca, na

n. 33 posse do seu juízo, negou a Ivan o estatuto de obra-prima absoluta e de um dos maiores filmes jamais em parte alguma realizados" ${ }^{21}$.

21. DA COSTA, João Bénard. Ivan Groznii. In: (org.). 100 dias, $\overline{100 \text { filmes. }}$ Lisboa: Costa \& Valério, 1994, p. 27.

22. EISENSTEIN, Sergei. Ivan the Terrible. London: Lorrimer Publishing, 1970 , p. 18.

\section{Expressão artística e experimentalismo formal}

Baseado em fatos históricos, Eisenstein tem a ideia de fazer um filme oficial sobre Ivan IV (Ivan Grozny), cujo roteiro termina na primavera de 1941. A empresa estatal de cinema da URSS vê no filme pretexto para exaltar o stalinismo. Ledo engano. A produção da Parte I (Ivan Grozny, 1944) começa em 1943 na Alma Atma Studio, mas a II Guerra Mundial impede a filmagem em Moscou. Já a Parte II (Ivan Grozny Boyarskii Zagovor, 1948) é filmada no estúdio Mosfilm, em 1945, e compreende alguns trechos coloridos, que são realizados a partir de estoque de película Agfa tomada dos alemães ao final da guerra. A Parte I é lançada em 30 de dezembro de 1944, no Teatro Bolshoi, com Josef Stálin no camarote de honra a aplaudir. E mais tarde, por incrível que possa parecer, obtém o prêmio Stálin, a mais alta condecoração civil da URSS, instituído em 1941, a homenagear autores com contribuições significativas nas áreas de ciências, literatura e arte.

Eisenstein termina a montagem da Parte II em 1948. Entretanto, o seu estado de saúde e as críticas o impedem de rodar a Parte III, apesar de estar minuciosamente escrita e preparada ${ }^{22}$. O que se vê, neste caso, é uma disputa político-ideológica. O líder da União Soviética Josef Stálin gosta da Parte I, espelho idealizado de Ivan. Mas proíbe a Parte II, descontente com a representação caricatural do czar. De fato, o paralelo entre Ivan e Stálin se faz de maneira óbvia. Stálin poderia aceitar a Parte II em que a linguagem é difícil e sinuosa, havendo personagens negativos, como a tia Eufrosínia e seu filho Vladimir que adquirem a mesma dimensão trágica de Ivan? Contradição. Eisenstein é visto como herói na Parte I. Mas como anti-herói na Parte II. Por este motivo, a Parte II jamais foi autorizada para exibição pública. E é lançada somente em 1958, após a morte de Stálin em 1953 e de Eisenstein em 1948.

A Parte I caracteriza-se pela ousadia na mesa de montagem. O plano primeiro do filme é a imagem isolada de uma coroa, para logo 


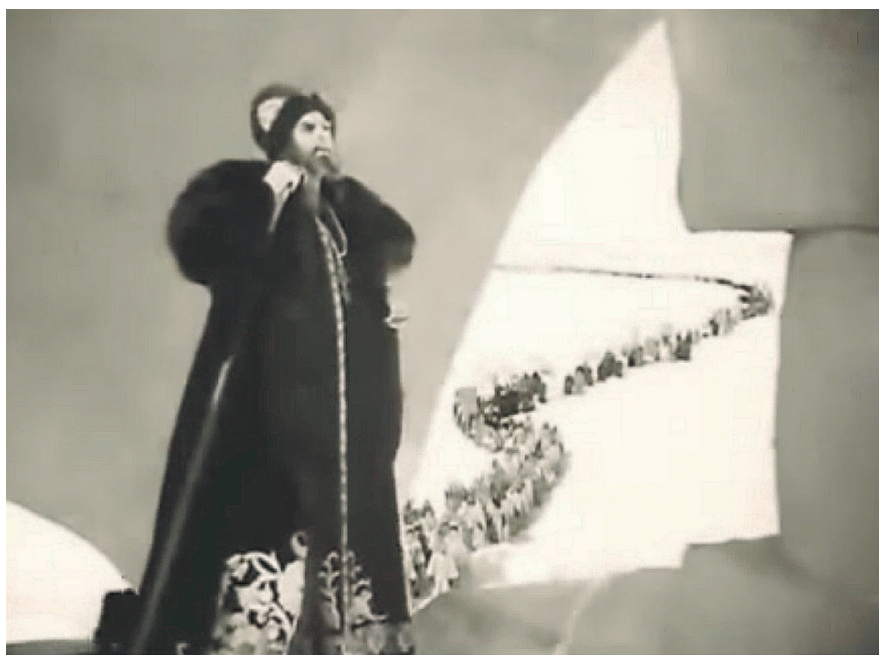

em seguida o Bispo de Novgorod adentrar a Igreja Cristã Ortodoxa de Moscou e abençoar o Arquiduque e Soberano Ivan IV, que se autocoroa o primeiro czar da Rússia. Ivan, apesar da oposição dos nobres e da guerra contra os tártaros, funda um exército permanente na tentativa de transformar uma sociedade medieval em império emergente. E a Igreja contribui para este estado unificado de um bilhão de hectares, que Ivan IV idealiza ser rico e autossuficiente.

Ivan casa-se com Anastásia, mas sua tia Eufrosínia envenena a czarina. E ele manifesta vingança à morte da esposa assassinada. Há a projeção grandiosa da sombra do czar na parede do palácio real, tendo em primeiro plano o globo terrestre e o tabuleiro de xadrez. A sequência final, com a composição em profundidade da lente $28 \mathrm{~mm}$, traz Ivan em primeiro plano e as linhas sinuosas do plano de fundo com o povo peregrino em longa fila. Ivan está isolado e o povo vem clamar para que volte a Moscou. A perspectiva criada pelo ponto de vista da cena (fig. 2) mostra o isolamento de Ivan ao alto e a proximidade do povo embaixo. De fato, seu longo e violento reinado transforma a Rússia em estado multiétnico e multirreligioso.

A Parte II, idealizada pelos desenhos de cenário do próprio diretor (storyboards), não prolonga a Parte I. O destino trágico do czar Ivan na narrativa torna-se evidente. A coligação de imagens e sons articula-se com a trilha sonora escrita pelo compositor ucraniano Sergei Prokofiev (1891-1953). E a pequena contribuição da cor é fundamental para garantir a produção de sentidos. Ivan, o Terrível - Parte II representa uma grande evolução de Eisenstein em
158

Atílio Avancini e

Fernanda Riscali

Revolução visual da arte de

Eisenstein em Ivan, o Terrível.

Fig. 2. Fotograma de Ivan, o Terrivel - Parte I (Sergei Eisenstein, 1944).

Czar Ivan (Nicolai Tcherkassov) 
ARS direção ao aprimoramento plástico. Nas duas partes, há a inclusão ano 16 da parceria entre o poder político e o elemento trágico, já trabalhan. 33 da pelo dramaturgo William Shakespeare (1564-1616). Diferente dos seus filmes anteriores, neste caso, Eisenstein distancia-se do movimento que envolve o coletivo. $\mathrm{O}$ centro de gravidade é priorizado em torno da individualidade e liderança de Ivan.

Os planos são longos, cuidadosamente dirigidos, e a narrativa gira em torno da temática loucura-conflito. Na união entre a tesoura e a teatralidade, há sucessivas tomadas de rostos caricaturais da corte de Ivan em close-up, reforçando a complexidade dos seres que cercam o czar. A narrativa visual é contemplativa e a mise-en-scène vistosa, com acento no aspecto distorcido e caricatural da família real, contrapondo os estereótipos de imagem hegemônica do modelo stalinista "realismo socialista".

Eisenstein é comedido no ritmo da montagem e prima por planos elaborados. A utilização do elemento profundidade de campo é intensa. A loucura não está isolada no czar, mas espalhada pelo palácio. É tocante contemplar Ivan puxar o companheiro Fyodor Kolichev pela capa e implorar a sua amizade. Ou a humilhação rastejante do czar a pedir piedade. Neste momento, a câmera de Eisenstein se afasta dos personagens e permite visualizar a vastidão e solidão do castelo - as roupas pretas e capas esvoaçantes do czar contrastam com o branco do salão real.

Ivan, o Terrivel é, como um todo, o trabalho mais metafórico de Eisenstein sobre os temas da ditadura, maldade e desumanidade, contando com o assassinato de familiares do czar: o primo Vladimir apunhalado e a esposa Anastásia Romanova, a czarina envenenada. Na Parte II, Stálin culpa Eisenstein por falta de orgulho e desaprova o retrato obtuso de Ivan, bem como a duração de cenas íntimas com a sua esposa - beijos não eram permitidos no cinema daquela época. Além do comprimento da barba ao evidenciar um símbolo fálico. De fato, Eisenstein apresenta a crueldade e a divindade do czar na dicotomia entre o óbvio e o obtuso.

\section{Luzes coloridas em vermelho e dourado}

O roteiro bem estruturado de Ivan, o Terrível - Parte II converge para encontrar o coração do filme, que é a sequência escolhi- 
da para a leitura de sentidos da mensagem fotográfica e cinematográfica, ou seja, o banquete com o primo Vladimir, considerado o momento êxtase e um dos dois movimentos coloridos do filme. Vale lembrar que o outro trecho colorido apresenta-se ao final quando o czar denuncia os inimigos da independência russa. O banquete trata-se de sequência matricial, uma vez que seus elementos ecoam em toda a narrativa. Os três fotogramas selecionados estão apresentados a seguir (fig. 3, 4 e 5).

A sequência narrativa, onde se encontram os três fotogramas selecionados, evidencia o czar Ivan desconfiado de que a tia Eufrosínia teria sido a responsável pelo envenenamento de sua esposa. A tia está também planejando a morte de Ivan e indica Pyotr para executá-lo. O fato é que Eufrosínia havia recebido de Ivan convite para um banquete, designando seu filho Vladimir e Pyotr para irem em seu lugar e cumprirem o plano do assassinato. Nesta sequência colorida, Ivan reafirma sua sagacidade e poder soberano, pois quem é assassinado é o seu próprio primo Vladimir.

Eisenstein sabe que o cinema é capaz de executar algumas técnicas narrativas melhor do que a literatura. No cinema, distintas perspectivas teóricas abordam os estudos cromáticos. Na primeira metade do século $\mathrm{XX}$, Eisenstein traz duas contribuições. O texto "Movimento da cor", publicado na coletânea Cinematismo, em que o cineasta aborda a cor como elemento dinâmico e um meio para expressar o movimento do pensamento. E, se o diretor estabelece uma cor contínua para um filme, "as peripécias internas do tema resultam em matizes de cor" ${ }^{23}$. Eisenstein afirma ainda, baseando-se no sistema aditivo, que não há ausência de cor em filmes preto e branco, uma vez que preto, branco e cinza são cores. O texto "Cor e significado”, publicado em O sentido do filme, aborda o significado simbólico da cor, uma concepção metafórica da obra cinematográfica.

De fato, o trecho colorido, em filme majoritariamente preto e branco, não está inserido por acaso. Um dos argumentos é a busca de Eisenstein pelo significado simbólico. E consequentemente pelo êxtase do espectador, que bem se integra ao patamar poético do sentido obtuso. Para Jacques Aumont, o êxtase é uma espécie de excesso psíquico ou transcendente. O termo é utilizado por Roland Barthes em A câmara clara para explicar a "loucura" contemplativa de determinadas fotografias ${ }^{24}$.
Atílio Avancini e

Fernanda Riscali

Revolução visual da arte de Eisenstein em Ivan, o Terrível.

23. Idem. Cinematismo Buenos Aires: Domingo Cortizo, 1982, p. 452.

24. BARTHES, Roland. A câmara clara. Rio de Janeiro: Nova Fronteira, 1984, p. 175. 
25. AUMONT, Jacques. As teorias dos cineastas. São Paulo: Papirus, 2004, p. 103.
Grande conhecedor das tradições pictóricas ocidentais e também de seu país, em Ivan, o Terrível - Parte II o diretor utiliza aspectos visuais dos ícones russos para nortear a concepção da imagem e reforçar aspectos da trama e dos personagens. A qualidade do ícone é transmitir proximidade ao plano celestial. Para alcançar esses objetivos, os iconógrafos usavam técnicas sistemáticas com relação ao cromatismo e à perspectiva. As cores vermelho e dourado neste filme vêm de dois contextos diferenciados: o tempo histórico de Ivan, que remete às cores dos ícones russos do século XVI e a época da produção do filme, em que o rubro sugere a cor revolucionária. Ao contrário do branco, que simboliza o intangível, o vermelho é uma cor que simboliza o humano, a plenitude vital da vida terrena, e o amor. Mas também pode significar o perigo, a violência, o medo, a tragédia, a desgraça, os mártires e o sangue de Cristo.

Sobre a fotografia de Ivan, o Terrivel - Parte II, há ainda a semelhança com a estética expressionista alemã: luz recortada, alto contraste, grandes sombras projetadas sobre o fundo. A iluminação feita por Eduard Tissé é uma das mais elaboradas dos filmes de Eisenstein. Obedece ao esquema de iluminação de três pontos, com a presença da luz principal, contraluz e luz de preenchimento. Há momentos em que a luz principal é lateral e vem de baixo, o que cria sombras alongadas e garante o volume nos rostos dos personagens. Além disso, a angulação da luz e a dureza das sombras reforçam a expressão extravagante do rosto do czar. Sempre há um foco de luz para destacar a figura de Ivan Grozny, evidenciando dualidade e conflito. Já os rostos dos outros personagens são iluminados frontalmente e com menos sombra.

\section{Análise dos processos de significação dos três fotogramas}

A seguir a leitura de sentidos dos três frames selecionados do filme Ivan, o Terrível - Parte II, inserido na sequência colorida 
do banquete. Como já desenvolvido no decorrer deste artigo, a metodologia de leitura imagética baseia-se na fundamentação teórica de Roland Barthes ao trabalhar os dois conceitos (óbvio e obtuso), além dos dois elementos de Erwin Panofsky (descrição e análise cultural), juntamente com o ponto de vista técnico-estético. A direção de Eisenstein coloca o efeito plástico e sonoro sempre em constante diálogo com o ritmo da narrativa. E a construção estética desta sequência sintetiza o conteúdo do filme.

É da corte de Ivan Vassilievich (1530-1584), o czar soberano da Rússia com o nome de Ivan IV, a inspiração cênica para Eisenstein utilizar mantos, joias e altares repletos de velas e incensos. Ivan sempre semeou o gosto pela missa e banquete. Mas também o sadismo doentio em aplicar tortura e execução em massa. Distante de ser comparado a um príncipe renascentista, foi mais um gótico ou medieval exótico pela expansão de seus domínios e ousadia de oito casamentos, em que sua primeira esposa foi Anastásia (interpretada por Ludmila Tzélikovskaya). Autocoroado, como evidencia o filme, o seu longo reinado de 37 anos (1547-1584) - conhecido como regime de terror ou tempo de tumulto -, foi protegido pelo Cristianismo ortodoxo russo e guiado pela própria inspiração pessoal em nome da Bíblia sagrada.

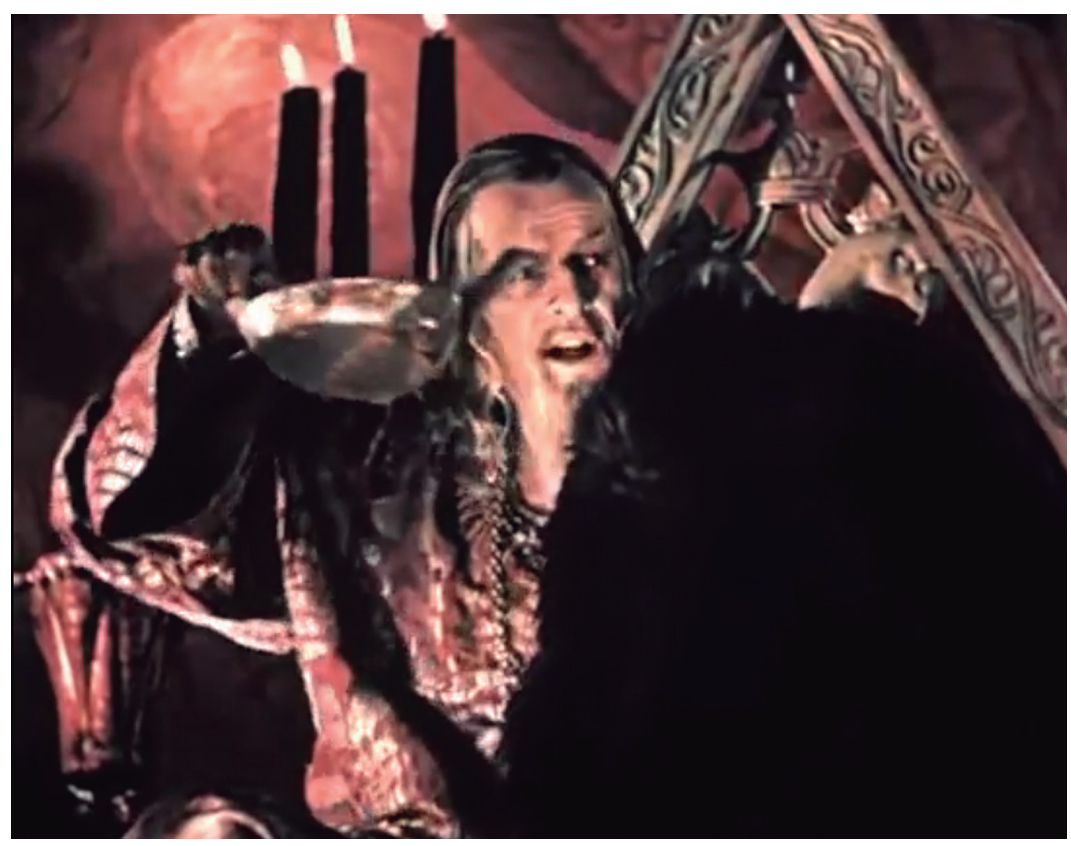

Atílio Avancini e

\section{Fernanda Riscali}

Revolução visual da arte de Eisenstein em Ivan, o Terrível.
Fig. 3. Fotograma de Ivan, o Terrivel - Parte II (Sergei Eisenstein, 1948). Czar Ivan (Nicolai Tcherkassov) 
Depois de uma cena de dança, Ivan é mostrado em seu assento real ao beber vinho (fig. 3). A forma triangular do trono é como uma seta direcionada para o alto, além de simbolizar culturalmente um lugar estruturado sobre base sólida. O trono é dourado e contrasta com o afresco vermelho ao fundo. O claro-escuro é dado pela grande massa preta em primeiro plano e pelas velas. A iluminação de Ivan vem da esquerda para a direita, em ângulo baixo, o que produz sombras em um dos lados do rosto e do manto. O escurecimento é importante para dar perspectiva, volume e densidade à cena. Com isso, acentua-se a dualidade dos aspectos divino (iluminado) e humano (sombreado).

O sentido óbvio é o poder exuberante, fartura, soberba e esbanjamento. Além do ser devasso e embriagado. O sentido obtuso é a despreocupação com a postura recatada (o vinho carrega algo de sagrado e profano). Esse excesso ou modo libertino e mundano do czar é ressaltado. Mas apesar do ruído, até certo ponto vago e grotesco, os sentidos altivo, majestoso e nobre se expressam nesta imagem do czar.

Ivan governa com a organização policial oprichnina (do russo antigo "estado separado") e um terço do território russo fica sob o seu poder. O czar se apropria das melhores terras com a guarda pessoal e implanta o absolutismo de terror na Rússia. O medo

Fig. 4. Fotograma de Ivan, o Terrível - Parte II. Czar Ivan (Nicolai Tcherkassovl

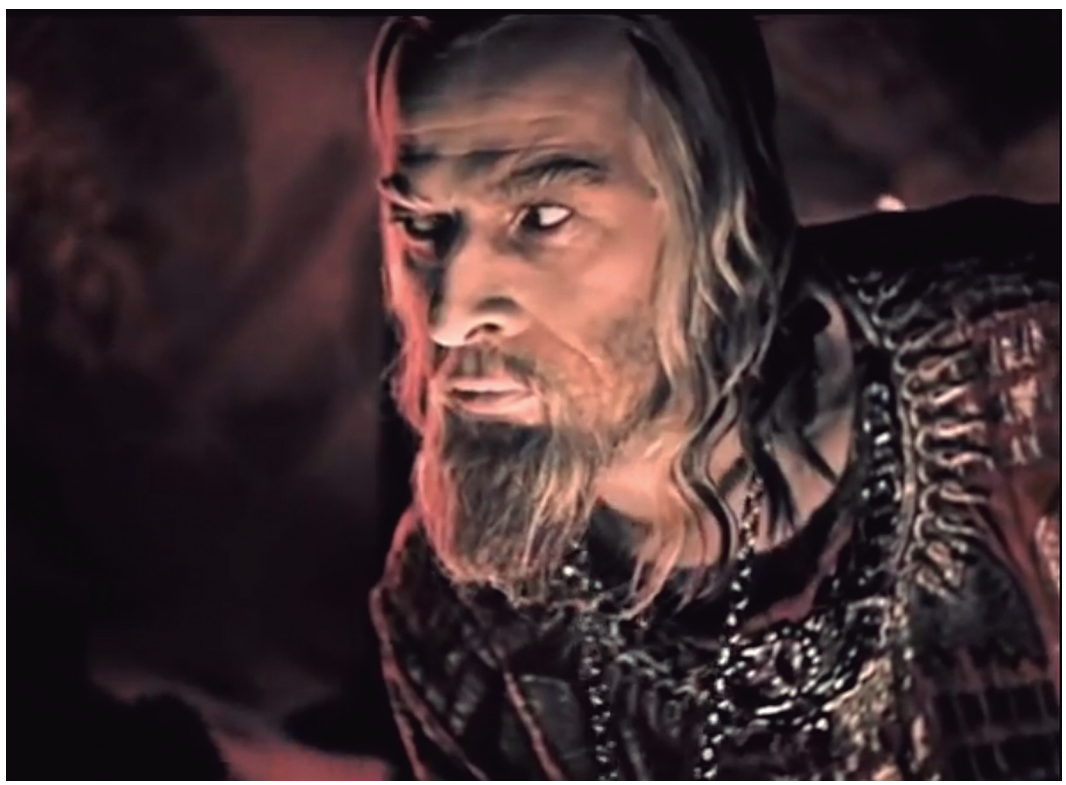


envolve o reino do homem paranoico, que é conhecido na época como Ivan Grozny (do russo antigo "horrendo"). Dentre outros, assassinou acidentalmente o neto, durante a gravidez da nora, e depois o próprio filho.

Este fotograma (fig. 4) é exemplo clássico de expressão, câmera em close-up e iluminação trabalhada por Eduard Tissé. A cena evidencia a instabilidade psicológica gerada pelo olhar do czar direcionado para fora do enquadramento: olhar desconfiado da direita para a esquerda. O posicionamento lateral do primeiro refletor (luz principal ou key light) gera sombras no rosto do czar. O segundo refletor (luz de preenchimento ou fill light) ameniza as sombras geradas pela luz principal e define o contraste da cena. E o terceiro refletor (contraluz ou back light), posicionado atrás, serve para destacá-lo do fundo. A iluminação de três pontos, bem como a lente e o ângulo de tomada, destacam a figura de Ivan, enfatizando a sua suspeita, desconfiança e o receio de ser enganado. É o homem solitário nos acordes da partitura musical de Prokofiev.

O ângulo normal de Ivan com a câmera posicionada aproximadamente na altura de seus olhos faz aproximar o espectador de seu rosto. Apesar de nobre, este ponto de vista permite ver a expressão facial e evidenciar o aspecto humano. A aura religiosa de Ivan que o protege é, entretanto, permeada por dúvidas, angústias e sentimentos. A aproximação traz o sentido óbvio de toda a desconfiança e inquietude estampadas: as rugas na testa, as sobrancelhas arqueadas, o nariz acentuado, o olhar enviesado. Mas o fotograma ainda faz ressaltar a barbicha, os cabelos longos e a corrente no pescoço. Sentidos obtusos na direção do erótico, fantasioso, excêntrico ou excessivo.

O czar esmaga os boyars (nobres proprietários de terra), mas seus inimigos estão entre o alto escalão da nobreza, clero e família, como a figura central da tia Eufrosínia (interpretada por Seraphina Birman). "Eu sou seu amigo, mas há planos para matá-lo", confessa seu primo Vladimir. Conflitos em torno da conspiração estão constantemente presentes. Mas Ivan, com a sua proteção divina e militar, além de sua autoridade, inteligência e vitalidade, manipula tudo ao redor. Inatacável e infalível, consolida o poder absolutista e dá unidade ao estado russo ameaçado por todos os lados.

Após ser acomodado no trono e vestido com os trajes nobres do czar, o filho de Eufrosínia, Vladimir, é coroado por Ivan (fig. 5).
Atílio Avancini e

Fernanda Riscali

Revolução visual da arte de Eisenstein em Ivan, o Terrível. 


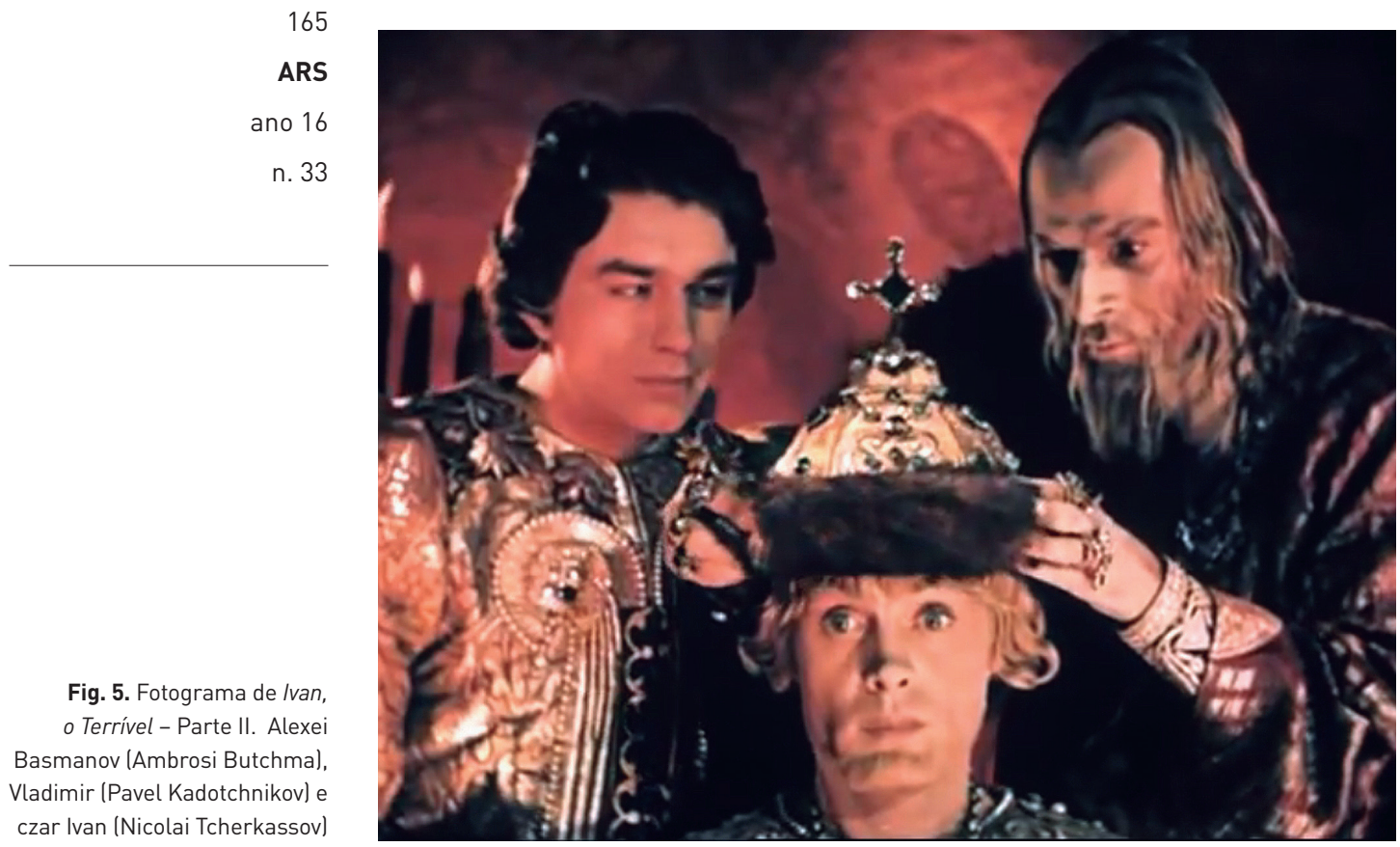

A expressão do jovem é de espanto. Ele traja as vestimentas reais e experimenta pela primeira vez a sensação de ser czar. Apesar de ter cedido a coroa - e a coroa simboliza o governante iluminado, soberano ou glorificado -, Ivan coloca a insígnia da autoridade com as suas próprias mãos em Vladimir, cujo rosto assustado e aflito evidencia o discurso do não lugar. "Qual o prazer de ser czar?”, pergunta Vladimir.

A imagem apresenta o equilíbrio estético do triângulo formado pelos três rostos, havendo ainda o triângulo da forma da coroa ao centro, que representa o poder como atividade central do Estado. E apesar de passar o trono, o czar Ivan se apresenta no ponto mais destacado da forma retangular do frame: o ponto áureo no alto à direita. A iluminação difere nos rostos de Ivan e Vladimir. Ivan tem sombra no olho esquerdo e o focado Vladimir recebe luz mais equilibrada nos dois lados do rosto, o que lhe garante sombras atenuadas com menos dramaticidade.

O sentido óbvio é o gesto de Ivan posando a coroa na cabeça ingênua do primo Vladimir. E o sentido obtuso se manifesta pela dimensão plástica e metafórica da irregularidade, além do modo depreciativo de Ivan e Basmanov estarem acima de Vladimir. A aparência enganadora do coroamento é evidenciada pelo ar dissimulado e pejorativo de Basmanov. E até pelos olhos arregalados e pela estranheza 
pastiche do inexperiente e atrapalhado Vladimir. Desde quando um rei empossado manifesta bizarra expressão? Seria o pressentimento de sua morte? Na sequência da cena fílmica, quando Vladimir, embriagado, deixa o recinto do banquete para adentrar a catedral, o czar entoa "Não recue, avance!”. E, neste momento, Vladimir confundido com o czar é assassinado pelas mãos de Pyotr.

\section{A coroa no espaço central como lugar simbólico do poder democrático}

É praticamente impossível analisar os três fotogramas isolados sem a visão completa da sequência fílmica. De fato, é só pela continuidade das imagens que percebe-se a montagem, bastante responsável pela construção de sentidos, que articula "conceitos com base no puro jogo poético das metáforas e metonímias”26. Ou seja, a série de imagens sequenciais sugere uma nova relação não presente nos três frames isolados. Mas os dois trechos coloridos trazem uma competência ao cumprirem o papel desejado, pois podem revelar relações importantes nos aspectos "informacional, estético e paradigmático" 27 .

O sentido obtuso "não está situado estruturalmente na leitura objetiva". E é "um significante sem significado de onde vem a dificuldade de nomear" ${ }^{\prime 2}$. De fato, verifica-se certa porosidade entre os códigos: informação-simbolismo e poético. Além de outros domínios que se interpenetram no referencial teórico de Barthes: a descrição e a análise cultural de Panofsky e o elemento técnico-estético.

Eisenstein opera em uma arte militante, alinhada à visão de "operários” do cinema, ao ideal socialista. Compreende-se, portanto, a vanguarda artística de Eisenstein pela luta política contra a autocracia do czar Ivan. As referências de Eisenstein - Ródtchenko e Viértov - contribuem para situar a arte a serviço do povo. Ivan, o Terrível, portanto, seria o prenúncio artístico dos ideais fracassados da revolução russa e da responsabilidade coletiva?

Eisenstein privilegia, entre o preto e branco e a cor, a forma e os tons misteriosos ou enigmáticos. A autoridade sagrada Ivan, entretanto, é personagem invadido pela dúvida, caricatural, além de estar isolado e roído pelo remorso. Atua de modo bipolar no jogo entre o homem e a divindade. A distorção é tal que está mais
Atílio Avancini e

Fernanda Riscali

Revolução visual da arte de Eisenstein em Ivan, o Terrível.

26. MACHADO, Arlindo. 0 filme-ensaio. In: SAMPAIO, Rafael; MOURÃO, Maria Dora (orgs.). Chris Marker, bricoleur multimídia. Rio de Janeiro: CCBB, 2009, p. 26.

27. GUIMARÃES, Luciano. Design da notícia e jornalismo visual no Notícias do Jardim São Remo. São Paulo: ECAUSP, 2017, p. 51

28. BARTHES, Roland. Op. cit., 1982, p. 55 
em luta consigo mesmo do que contra os inimigos externos. A arte do cinema de conflito se manifesta de modo complexo a partir dos

29. DOSTOIÉVSKI, Fiódor. Os irmãos Karamázov. Porto Alegre: L\&PM, 2015, p. 298.

30. Ibidem, p. 302

31. MARIE, Michel. Depoimento cit., 2016. sentidos aqui analisados: óbvio, obtuso, descrição, análise cultural e técnico-estético. A montagem trabalha como experimento ousado e de característica dramática no quadro composicional.

É função do cinema retomar momentos históricos, personagens célebres e narrativas inesquecíveis. Ivan, o Terrivel assume o papel de registrar e disseminar história ou lenda que não deve ser esquecida: o primeiro czar da Rússia unificada exerce o seu poder divino sobre os homens, mas em regime tirânico e autoritário. $\mathrm{O}$ escritor Fiódor Dostoiévski, na visão crítica de decifrar o cotidiano social, afirma que a maioria dos líderes políticos só estão interessados "em lucro e vantagens sem se importarem com o povo ou com a nação" 29 . E a produção de sentidos do filme almeja "criar uma nova nação em que todas as pessoas possam viver em igualdade" ${ }^{30}$. Não por acaso, este último fotograma (fig. 5) representa a coroa gloriosa, simbolizando o poder político, no centro da imagem. O centro, neste caso, pode ser lido culturalmente como o lugar ideal da busca pela democracia e diálogo.

O filme de Eisenstein, instrumento de denúncia, se eterniza ao ser legitimado como registro histórico do passado e metáfora do presente. Não por acaso, Sergei Eisenstein foi elevado à condição de totem da crítica cinematográfica internacional. Não visava trabalhar pelo cinema reduzido à projeção na tela, mas como instrumento de reflexão social a partir do discurso e compromisso ideológico. "A tese de Eisenstein é demonstrar que com eficácia política e lirismo se pode fazer a revolução"31. De fato, a leitura de sentidos da mensagem fotográfica e cinematográfica contribui para confirmar a dimensão transcendente, enigmática, conflituosa, elíptica e aprofundada da obra de Eisenstein.

A tecnologia digital amplia hoje o acesso à informação. E garante a Ivan, o Terrível o formato multimídia para facilitar a pluralização do conhecimento histórico. A linguagem de conflito em Eisenstein revela a dimensão divina, terrível e horrenda do czar Ivan. E traça paralelos com os expurgos promovidos pelo stalinismo. Eisenstein é premiado por Stálin na Parte I. Mas enfrenta o marechal dos exércitos soviéticos ao transgredir a imposição do Estado na formatação ideológica da Parte II. 
Quando derrubaram o czar, em 1917, o povo russo acostumado à referência da liderança do czar, necessitava de alguém que o substituísse. O escritor norte-americano John Steinbeck conta a sua experiência de repórter em Moscou no ano de 1947. "O ícone faz parte dos hábitos mentais russos... os russos amam tanto Stalin que o querem sempre presente... seja qual for o motivo, ninguém passa um segundo fora do alcance do olhar sorridente, pensativo ou severo de Stalin"32.

A história hoje se repete? Karl Marx - ao discutir temas como exploração social, pobreza e desigualdade - continua contemporâneo. De fato, no vácuo gerado pelo colapso econômico do neoliberalismo do presidente Boris Yeltsin, o mito Vladimir Putin se torna modelo do populismo conservador. "Não tenho motivos para ser otimista. A Rússia não tem líderes capazes suficientes para substituir Vladimir Putin no poder. Com isso, só podemos esperar por um novo ditador"33.

A abertura do filme Ivan, o Terrivel - Parte I apresenta nuvens brancas e pretas passando em ritmo acelerado. E traz como legenda esta citação histórica:

Uma nuvem negra está se formando. Um crepúsculo sangrento se aproxima. Os boyars tramaram um plano sinistro contra a autoridade do Czar que agora estão executando. Este é um filme sobre um homem que foi o primeiro a unir esta nação no século XVI. Um príncipe de Moscou, que criou um único e poderoso estado de principados separatistas divididos. Um guerreiro soberano que anunciou a glória militar de nossa Pátria-Mãe através do Oriente e do Ocidente. O primeiro reinante que, para alcançar estas grandes marcas, coroou-se como o Czar de Todas as Rússias ${ }^{34}$.

A luta política de Eisenstein, cuja abertura faz anunciar tempos de crise, enfatiza a distorção dos governantes, que estão acima das leis, confrontada com as aspirações humanas de justiça. Faz parte do projeto cinematográfico do diretor afastar a humanidade das atrocidades dos regimes políticos autoritários: proteger liberdades coletivas e individuais, fomentar a igualdade social, minimizar a exploração econômica, universalizar o direito de aprendizado e evitar a pobreza desesperançada. A revolução
Atílio Avancini e

Fernanda Riscali

Revolução visual da arte de

Eisenstein em Ivan, o Terrível.

32. STEINBECK, John. Um diário russo: John Steinbeck e Robert Capa. São Paulo: Cosac Naify, 2010, p. 77.

33. ALEKSIEVITCH, Svetlana. Doçura e ceticismo. 0 Estado de S. Paulo, São Paulo, 2 jul. 2016, Caderno 2, p. C5. Depoimento a Ubiratan Brasil.

34. Ivan, o Terrível - Parte I. Sergei Eisenstein, Rússia, 1944. 
ARS visual de Eisenstein resulta no embate entre o óbvio e o obtuso, ano 16 no cuidado técnico-estético da composição fotográfica, na valon. 33 rização cultural, na coligação de imagens e sons, no êxtase emocional E sintetiza dois olhares dramatúrgicos e poéticos sobre o oscilante e contraditório Ivan, que representa o poder distorcido: o mito populista e o Cristo místico.

\section{Bibliografia}

ALBERA, François. Eisenstein e o construtivismo russo. São Paulo: Cosac \& Naify, 2002.

ALEKSIEVITCH, Svetlana. Doçura e ceticismo. O Estado de S. Paulo, São Paulo, 2 jul. 2016, Caderno 2, p. C5. Depoimento a Ubiratan Brasil.

AUMONT, Jacques.; MARIE, Michel. L'analyse des films. Paris: Nathan, 1988.

AUMONT, Jacques. As teorias dos cineastas. São Paulo: Papirus, 2004.

BARTHES, Roland. A câmara clara. Rio de Janeiro: Nova Fronteira, 1984.

. L'obvie et l'obtus. Paris: Éditions du Seuil, 1982.

. Euvres complètes (tome V). Paris: Éditions du Seuil, 2002.

CARVALHO, Luiz Gustavo. Assim vivíamos. Curador da exposição fotográfica de Vladimir Lagrange. Caixa Cultural, São Paulo, 2015.

DA COSTA, João Bénard. Ivan Groznii. In: . (org.). 100

dias, 100 filmes. Lisboa: Costa \& Valério, 1994, p. 27.

DOSTOIÉVSKI, Fiódor. Os irmãos Karamázov. Porto Alegre: L\&PM, 2015. 
EISENSTEIN, Sergei. Sobre a questão da abordagem materialista da forma. Kino-Journal ARK, Moscou, n. 4-5, 1925.

. O sentido do filme. Rio de Janeiro: Jorge Zahar, 2002a.

. A forma do filme. Rio de Janeiro: Jorge Zahar, 2002b.

. Ivan the Terrible. London: Lorrimer Publishing, 1970.

. Cinematismo. Buenos Aires: Domingo Cortizo, 1982.

FREITAS, Nanci de. O velho e o novo: tensão entre experimentação artística no cinema de Eisenstein e as demandas ideológicas soviéticas. Revista ArtCultura, Uberlândia, v. 13, n. 22, jan.-jun. 2011.

GROYS, Boris. Stalinism as aesthetic phenomenon. In: EFIMOVA, Alla; MANOVICH, Lev (org.). Tekstura. Chicago: The University of Chicago Press, 1993.

GUIMARÃES, Luciano. Design da notícia e jornalismo visual no Notícias do Jardim São Remo. São Paulo: ECA-USP, 2017.

LAVRÉNTIEV, Aleksandr. Aleksandr Ródtchenko: começos da vanguarda fotográfica na Rússia. In: RÓDTCHENKO, A. Aleksandr Ródtchenko. São Paulo: IMS, 2010.

MACHADO, Arlindo. O filme-ensaio. In: SAMPAIO, Rafael; MOURÃO, Maria Dora (orgs.). Chris Marker, bricoleur multimídia. Rio de Janeiro: CCBB, 2009, p. 26.

MARIE, Michel. Depoimento a Atílio Avancini. Projeto Revolução visual de Sergei Eisenstein. Universidade de São Paulo, São Paulo, 14 abr. 2016.

MARX, Karl. A miséria da filosofia. São Paulo: Editora Ícone, 2004.

RÓDTCHENKO, Aleksandr. Aleksandr Ródtchenko. São Paulo: IMS, 2010.
Atílio Avancini e

Fernanda Riscali

Revolução visual da arte de

Eisenstein em Ivan, o Terrível. 
STEINBECK, John. Um diário russo: John Steinbeck e Robert

\section{n. 33} Capa. São Paulo: Cosac Naify, 2010.

VIANNA, Alexander Martins. Eisenstein e o cinema soviético. Blog da Revista Espaço Acadêmico, 15 ago. 2012. Disponível em: $<$ https://espacoacademico.wordpress.com/2012/09/12/eisensteine-o-cinema-sovietico-ii/>. Acesso em: 11 jul. 2018.

Atílio Avancini é professor doutor do Programa de Pós-Graduação de Meios e Processos Audiovisuais da Escola de Comunicações e Artes da Universidade de São Paulo [PPGMPA/ECA/USP].

Artigo recebido em 22 de maio de 2018 e aceito em 08 de julho de 2018.
Fernanda Riscali é doutoranda Programa de Pós-Graduação de Meios e Processos Audiovisuais da Escola de Comunicações e Artes da Universidade de São Paulo [PPGMPA/ECA/USP]. 